\title{
Carbonyl Groups in Lignin
}

\author{
IV *. Infrared Absorption Studies and Examination of the \\ Volumetric Borohydride Method **
}

\author{
JOSEF MARTON, ERICHADLER and KARL-INGVAR PERSSON
}

Institutionen för organisk kemi, Chalmers Tekniska Högskola, Göteborg, Sweden

\begin{abstract}
Infrared absorption studies have shown that a mixture of sodium borohydride-reduced Björkman lignin with isopropylconiferyl aldehyde $\left(0.033\right.$ mole per $\mathrm{OCH}_{3}$ of the mixture), arylpropanone-1 model substances $\left(0.07\right.$ mole/ $\left./ \mathrm{OCH}_{3}\right)$, and arylpropanone.2 models $(0.11$ mole $/ \mathrm{OCH}_{3}$ ), i.e., a total of 0.21 carbonyl groups per $\mathrm{OCH}_{3}$, gives an absorption pattern in the region of the carbonyl stretching vibration very similar to that given by untreated Björkman lignin.

Reduction of the latter lignin with sodium borohydride causes the hydroxyl content to increase by 0.20 hydroxyl groups per $\mathrm{OCH}_{3}$.

An attempt has been made to explain the discrepancy between the carbonyl values obtained as above as well as by the oximation method (about $0.20 \mathrm{CO} / \mathrm{OCH}_{3}$ ) and those found by Gierer and Söderberg with a volumetric borohydride method (about $0.40 \mathrm{CO} / \mathrm{OCH}_{3}$ ). Reexamination of the latter method showed that values which are reasonably close to 0.20 are obtained if air is excluded from the apparatus.1
\end{abstract}

$\mathrm{O}$ ximation of Björkman lignin with hydroxylamine hydrochloride at room temperature and titration of the hydrochloric acid liberated indicated the presence of 0.20 carbonyl groups per methoxyl ${ }^{1}$. (In the following, the abbreviation "CO" will be used for "carbonyl groups".) Examination of the spectral changes taking place on reduction of the lignin with sodium borohydride ${ }^{2}$ showed that this total number of $\mathrm{CO}$ included, per $\mathrm{OCH}_{3}$, about 0.01 coniferyl aldehyde and 0.01 aryl-a-ketone units with free phenolic 4-hydroxyl groups and, in addition, 0.03 coniferyl aldehyde and $0.05-0.06$ aryl-a-ketone units, in which the 4-hydroxyl group was etherified. The difference between the

* Part III, see Ref. ${ }^{3}$.

** Preliminary accounts of the results reported in Parts II-IV were given (by E.A.) at a colloquium at Chemisches Institut der Universität, Heidelberg, July 29, 1959 and (by J.M.) at Tionde Nordiska Kemistmötet, Stockholm, August 17-22, 1959; cf. Svensk Kem. Tidskr. 71 (1959) 439. 
total number of $\mathrm{CO}(0.20)$ and that of the conjugated carbonyl structures mentioned, i.e., about $0.10 \mathrm{CO}$, was attributed to isolated keto groups (in the $\beta$-position of the propane side-chains) ${ }^{2}$. Similar results regarding the number of carbonyl-containing chromophores were obtained by spectrochemical investigation of the hydrogenation of Björkman lignin over a palladiumbarium sulphate catalyst ${ }^{3}$. Finally, the hydrogen consumption observed on hydrogenation over a nickel boride catalyst revealed ${ }^{3}$ that the sum of carbonyl and ethylene groups in Björkman lignin does not exceed 0.30. Since the number of ethylene groups was found to be $0.06-0.08(0.03-0.04$ each present in coniferyl aldehyde and coniferyl alcohol groups, respectively) ${ }^{3}$, a total number of $0.22-0.24 \mathrm{CO} / \mathrm{OCH}_{3}$ was obtained by that method.

In contrast with these results, Gierer and Söderberg ${ }^{4}$, using a volumetric borohydride method, arrived at values of $0.4 \mathrm{l}-0.44 \mathrm{CO} / \mathrm{OCH}_{3}$, i.e., one carbonyl group per about 2.5 arylpropane units. Whereas the figures found in this laboratory more or less impart to the carbonyl groups the role of accessory structural elements - although possibly important in certain reactions of the lignin molecule - the values found by Gierer and Söderberg would imply that the carbonyl groups are of major structural importance in lignin. This situation prompted further investigation of the problem regarding the number of these groups.

The borohydride method was developed by Lindberg and co-workers $s$ especially for the estimation of carbonyl groups in carbohydrates. In this method, the sample is allowed to react with an alkaline solution of sodium or potassium borohydride. During the reaction period some hydrogen is evolved by sponteneous decomposition of borohydride. Hydrogen is then liberated from the unconsumed borohydride with sulphuric acid, and the difference between the total amount of hydrogen obtained similarly in a blank and that found in the experiment yields the amount of carbonyl groups reduced. Applying this method to lignin, Gierer and Söderberg ‘ allowed potassium borohydride to react for $5 \mathrm{~h}$ with an alcoholic alkaline solution of the lignin.

To explain the discrepancy between the $\mathrm{CO}$ values found by oximation $(0.20)$ and by the volumetric borohydride method $(0.41-0.44)$, Gierer and Söderberg made the following alternative suggestions.

1) The reaction between the carbonyl groups of lignin and hydroxylamine hydrochloride is incomplete, whereas their reduction by borohydride goes to completion.

2) A certain fraction of the carbonyl groups in lignin is present in a "masked" form, e.g., as hemiacetals, which are unreactive towards hydroxylamine but reducible by borohydride.

Regarding possibility (1), it was actually found by Gierer and Söderberg 4 as well as in our laboratory ${ }^{2}$ that certain aryl-a-ketones reacted very slowly with hydroxylamine but rapidly with borohydride. For instance, ketone V, when treated with hydroxylamine hydrochloride for $5 \mathrm{~h}$ at room temperature, gave only $3 \%$ of the calculated amount of oxime, but was completely reduced on $5 \mathrm{~h}$ treatment with potassium borohydride. However, this pronounced difference regarding the reactivity of certain a-ketones in the two methods cannot be responsible for the difference in the lignin carbonyl values obtained. Being aware of the low reactivity of certain types of aryl a-ketones, we had used in our oximation experiments with lignin a reaction time of $500 \mathrm{~h}$, which

Acta Chem. Scand. 15 (1961) No. 2 
yielded the value of $0.20 \mathrm{CO} / \mathrm{OCH}_{3}$. Under these conditions the majority of the ketone model substances reacted completely, and the extremely "hindered" ketone $\mathrm{V}$ was converted to $60 \%{ }^{2}$. Furthermore, as mentioned above, the number of aryl $a$-ketones in Björkman lignin was shown by two independent methods ${ }^{2,3}$ to be only $0.06-0.07$ per $\mathrm{OCH}_{3}$. Hence, the slow oximation of such ketones could not possibly explain the difference between the oximation and the volumetric borohydride values.

Gierer and Söderberg ${ }^{4}$ found that ketone V, when oximated at reflux temperature, reacted almost completely within $5 \mathrm{~h}$, and, furthermore, that Björkman lignin, under similar conditions, gave a CO value of 0.25 instead of the value of 0.20 obtained on oximation at room temperature. It must be pointed out, however, that the increased value observed after oximation of lignin in boiling solution, may well be due to the formation of new keto groups ("Hibbert ketones"), brought about by the hydrochloric acid liberated; $c f$. the acidolysis of guaiacylglycerol-a-aryl ether units studied by Adler, Pepper and Eriksoo ${ }^{6,7}$.

Since the number of conjugated carbonyl groups, i.e., the sum of aryl $a$ ketone groups and coniferyl aldehyde groups, has been shown to be limited to about 0.10 per $\mathrm{OCH}_{3}$, a total $\mathrm{CO}$ content of $0.41-0.44$ would require the presence of about $0.3 \beta$-keto groups (concerning the occurrence of "masked" carbonyl groups, see below). This possibility, however, is eliminated by the weakness of the carbonyl absorption in the region of $5.8 \mu$, as shown in the IR spectrum of Björkman lignin (Fig. 1,a). Further evidence supporting the view that the carbonyl content of Björkman lignin is confined to about 0.1 each of conjugated and isolated carbonyl groups is provided by the following experiments.

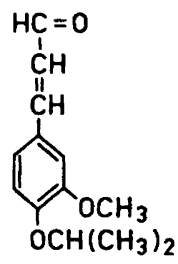

I

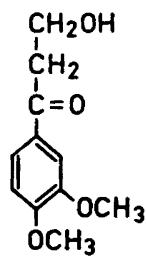

II

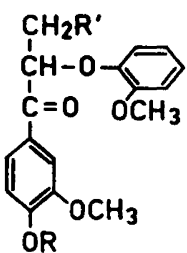

$\begin{array}{lll}\text { III: } & R=R^{\prime}=H \\ \text { I : } & R=\mathrm{CH}_{3} ; \quad R^{\prime}=\mathrm{H} \\ \text { I: } & \mathbf{R}=\mathrm{CH}_{3} ; \quad \mathrm{R}^{\prime}=\mathrm{OH}\end{array}$<smiles>[R]CC(=O)Cc1cc([R])c(O)c(OC)c1</smiles>

II: $\mathrm{R}=\mathrm{OCH}_{3} ; \mathrm{R}^{\prime}=\mathrm{H}$

III: $\mathrm{R}=\mathrm{H}^{\prime} ; \mathrm{R}^{\prime}=\mathrm{OH}$

In the IR spectrum of untreated Björkman lignin (Fig. 1, a) there is a comparatively strong absorption band near $6 \mu$ (coniferyl aldehyde and aryl $a$-ketone groups, cf. also Refs. ${ }^{2,8}$ ) as well as a weaker band or shoulder at about $5.8 \mu$ (isolated $\mathrm{CO}$ ). The former band disappears when the lignin is reduced with sodium borohydride (Fig. 1, b). Some low-intensity absorption around $5.8 \mu$ is left, probably due to minor amounts of carboxyl groups. The appearance of the carbonyl region of untreated lignin can be restored rather satisfactorily by adding model substances of the coniferyl aldehyde (I) and aryl $a$-ketone (II-V) as well as the $\beta$-ketone (VI-VII) type to the carb- 


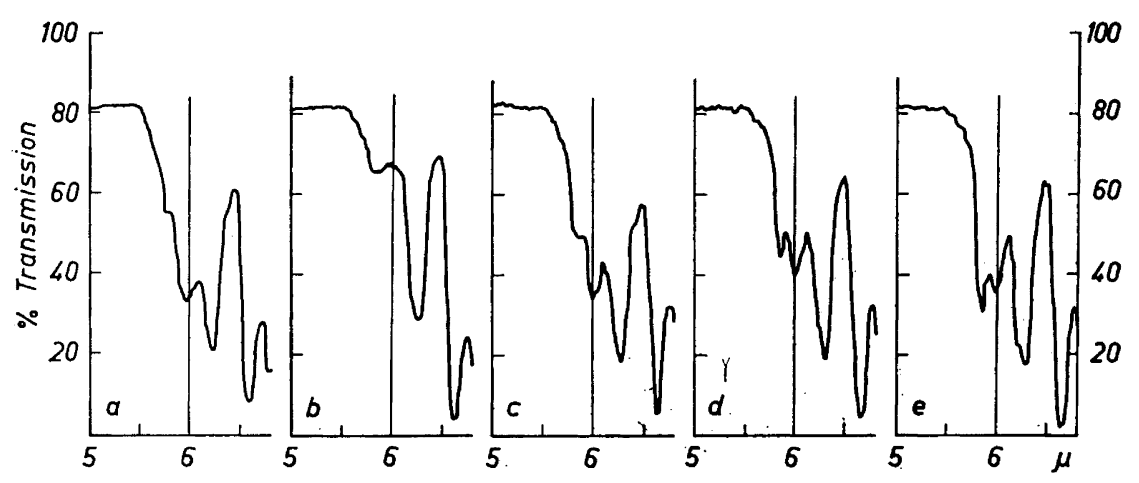

Fig. 1. Infrared absorption of Björkman lignin (a), $\mathrm{NaBH}_{4}$-reduced Björkman lignin (b), and mixtures of the $\mathrm{NaBH}_{4}$-reduced lignin with crystalline model substances, the concentrations of which are given in moles per mole of $\mathrm{OCH}_{3}$ present in the mixture (for model compounds containing more than one $\mathrm{OCH}_{3}$, only one $\mathrm{OCH}_{3}$ group has been taken into consideration): c) $\mathrm{NaBH}_{4}$-lignin plus 0.033 isopropylconiferyl aldehyde (I); $\alpha$-ketones: 0.05 II, 0.01 III, 0.01 IV; $\beta$-ketones: 0.05 VI, 0.06 VII. Total CO added, $0.21 . d) 0.04$ isopropylconiferyl aldehyde (I); a-ketone: $0.07 \mathrm{~V}$; $\beta$-ketones: $0.07 \mathrm{VI}$; 0.08 VII. Total CO added, 0.26. e) 0.04 isopropylconiferyl aldehyde (I); $\alpha$-ketone: $0.07 \mathrm{~V}$; $\beta$-ketones: 0.14 VI: 0.15 VII. Total CO added, 0.40 .

onyl-free $\mathrm{NaBH}_{4}$-lignin. Fig. 1, $c$ shows the IR spectrum of a mixture of borohydride-reduced (CO-free) Björkman lignin with the following amounts of the model substances (given as moles per mole of total $\mathrm{OCH}_{3}$ present in the mixture): 0.033 coniferylaldehyde, 0.07 aryl $a$-ketone, and $0.11 \beta$-ketone (total, $\left.0.21 \mathrm{CO} / \mathrm{OCH}_{3}\right)$. If the amount of the $\beta$-ketone models is increased to give 0.15 $\beta$ - $\mathrm{CO} / \mathrm{OCH}_{3}$ (Fig. 1, $d$ ) or $0.30 \beta-\mathrm{CO} / \mathrm{OCH}_{3}$ (Fig. 1, $e$ ), the latter mixture corresponding to a total of $0.40 \mathrm{CO} / \mathrm{OCH}_{3}$, as claimed by Gierer and Söderberg ${ }^{4}$, the shortwave carbonyl absorption becomes far stronger than that shown by Björkman lignin $(1, a)$.

These results eliminate the possibility that the high carbonyl values of Gierer and Söderberg might be caused by the presence of (about 0.2 ) $\beta$-keto groups unable to react with hydroxylamine.

The alternative suggestion of Gierer and Söderberg postulated that oximation gave false low carbonyl values because of the presence of hemiacetal (hemiketal) groupings. However, an attempt by them to find experimental support for this idea was unsuccessful. They found that methylation of lignin with methanolic hydrochloric acid at room temperature did not diminish the number of "carbonyl" groups as determined by the borohydride method. Had hemiacetal groupings been present, they would have been methylated and become resistant to borohydride. For further clarification of the hemiacetalproblem, the change of the number of hydroxyl groups taking place on borohydride reduction of Björkman lignin has now been examined.

By acetylation (Verley-Boelsing, $c f$. also Ref. ${ }^{9}$ ), Björkman lignin was found to contain $1.40 \mathrm{OH} / \mathrm{OCH}_{3}$ (uncorrected for small amounts of carbohydrates present ${ }^{10}$ ), whereas $1.60 \mathrm{OH} / \mathrm{OCH}_{3}$ were found in the $\mathrm{NaBH}_{4}$-lignin. The

Acta Chem. Scand. 15 (1961) No. 2 
increase by $0.20 \mathrm{OH} / \mathrm{OCH}_{3}$ is in harmony with the presence of $0.20 \mathrm{CO} / \mathrm{OCH}_{3}$ in the untreated lignin. If, in addition, 0.2 hemiacetal groupings had been present, these would have been reduced according to

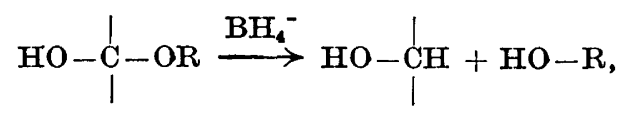

and thus would have given rise to the formation of an additional amount of $0.2 \mathrm{OH}$ groups. (This type of reduction is well-known from sugars as well as from other cases, $c f$. the reduction of the Wieland-Gumlich aldehyde ${ }^{11}$ ).

None of the results reported above provides any support for the presence, in lignin, of free or half-acetalised keto groups unreactive towards hydroxylamine, which might have explained the high carbonyl values obtained by Gierer and Söderberg. In fact, both the infrared absorption studies and the $\mathrm{OH}$ determination seem to constitute confirmative evidence for the correctness of the oximation value, i.e., about 0.20 total $\mathrm{CO} / \mathrm{OCH}_{3}$.

The high borohydride consumption, indicating about $0.4 \mathrm{CO} / \mathrm{OCH}_{3}$, as found by Gierer and Söderberg, then still required an explanation. The method was therefore reexamined.

\section{REEXAMINATION OF THE VOLUMETRIC BOROHYDRIDE METHOD}

In accordance with Gierer and Söderberg ${ }^{4}$, a borohydride consumption corresponding to a value of about $0.4 \mathrm{CO} / \mathrm{OCH}_{3}$ was found for Björkman lignin, if the experimental conditions given by these authors were used (Fig. 2 , curve $a$; reaction time, $5 \mathrm{~h}$ ). A considerably higher value, viz., $0.55 \mathrm{CO} / \mathrm{OCH}_{3}$, was obtained, if the reaction mixture was subject to magnetic stirring during the reduction period (Fig. $\mathcal{2}$, curve $b$; reaction time, $5 \mathrm{~h}$ ). Under similar

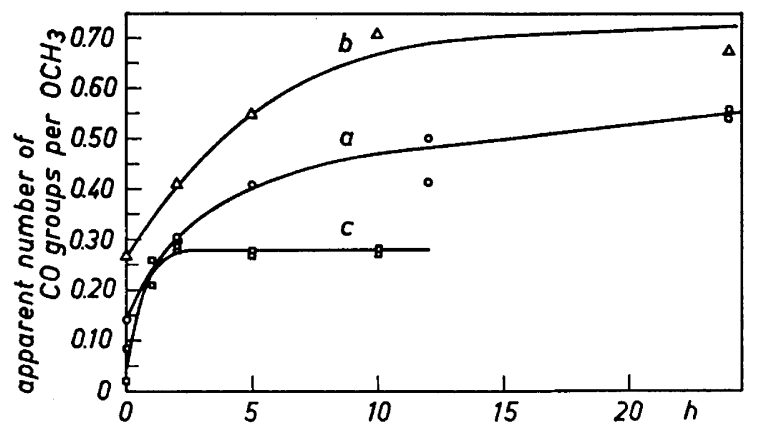

Fig. 2. Estimation of carbonyl groups by the volumetric borohydride method. Björkman lignin, $90-100 \mathrm{mg} ; 0.13 \mathrm{M} \mathrm{KBH}_{4}$ in $0.1 \mathrm{~N}$ aqueous $\mathrm{NaOH}(3 \mathrm{ml})$, and $0.10 \mathrm{M} \mathrm{H}_{3} \mathrm{BO}_{3}$ in $96 \%$ ethanol $(4 \mathrm{ml})$. The reaction was stopped by the addition of $2 \mathrm{~N} \mathrm{H}_{2} \mathrm{SO}_{4}(\mathrm{lml})$. Curve $a$ : Air in the gas space, no stirring of the reaction mixture. Curve $b$ : Air in the gas space, magnetic stirring of the reaction mixture. Curve $c$ : Nitrogen in the gas space, no stirring of the reaction mixture. The values given at "zero time" were obtained on $5 \mathrm{~h}$ treatment of a $\mathrm{NaBH}_{4}$-reduced Björkman lignin. 
conditions, an appreciable "borohydride consumption", corresponding to a content of $0.26 \mathrm{CO} / \mathrm{OCH}_{3}$ was also obtained with a $\mathrm{NaBH}_{4}$-reduced, i.e., carbonyl-free, lignin, and figures of 1.05 and $1.97 \mathrm{CO} / \mathrm{OCH}_{3}$, which were quite obviously too high, were similarly found for Brauns lignin and a commercial kraft lignin, respectively. Furthermore, it was found that the end-point was not reached after a reaction time of $5 \mathrm{~h}$, as used by Gierer and Söderberg, increasing $\mathrm{CO}$ values being obtained, if the reaction was carried on for prolonged periods of time. This was true whether the reaction mixture was stirred or not (Fig. 2, curves $a$ and $b$ ).

Since the final gas mixture in the determination is a mixture of hydrogen and air, a reaction consuming either hydrogen or one of the constituents of air could produce such effects. Bearing in mind the method of preparing Björkman lignin three such reactions immediately come to mind, viz. (1) the reaction of some of the liberated hydrogen with the oxygen in the air, (2) oxidation of the lignin by the gaseous oxygen and (3) the hydrogenation of the ethylene groups in lignin $\left(0.06-0.08 \mathrm{per} \mathrm{OCH}_{3}\right.$, see Ref. $\left.{ }^{3}\right)$. These reactions could be catalysed by contaminating traces of heavy metals or heavy metal ions present in the reaction mixtures. Emission spectrographic analysis * of the ash (about $0.1 \%$ ) obtained from Björkman lignin revealed a comparatively high content of heavy metals $(\mathrm{Fe}>\mathrm{Ni}>\mathrm{Cr}$ ), probably originating from the grinding of the wood in a vibratory stainless steel ball mill.

In a volumetric borohydride experiment, the lignin was replaced by $25 \mathrm{mg}$ of the wood powder residue which remains after the extraction of lignin from the milled wood with dioxan according to Björkman. (This wood powder has a gray colour due to the presence of contaminating metal.) After a reaction time of $5 \mathrm{~h}, 8 \mathrm{ml}$ of gas (corresponding to $10 \mathrm{mg}$ of carbonyl!) had been consumed as compared with a blank without wood meal. In a second experiment, the apparatus was filled with hydrogen before the components were mixed; the gas consumption was then only $1.3 \mathrm{ml}\left(\mathrm{of}_{2}\right)$. This suggests that the major part of the gas consumption in the first experiment was due to catalytic oxidation, by air present in the apparatus, of hydrogen evolved from the borohydride (and, less probably, also of the wood meal).

The assumption that the procedure used by Gierer and Söderberg involves a consumption of hydrogen and of oxygen from the gas phase by the reactions mentioned above, would explain the effect of the reaction time as well as of the stirring of the reaction mixture.

Concerning the proper nature of the catalysts assumed to act in this system, it may be pointed out that heavy metal salts react with borohydride to form borides, which have shown to be excellent hydrogenation catalysts ${ }^{12,13,3}$. Also, such borides as well as heavy metals in a finely divided state will catalyse the combustion of hydrogen. Furthermore, they accelerate the decomposition of borohydrides with the formation of hydrogen ${ }^{14}$.

If, in the borohydride reduction of Björkman lignin, the apparatus was filled with hydrogen or nitrogen rather than air, the values found for the borohydride consumption were considerably lower. Values of $0.27-0.29$ $\mathrm{CO} / \mathrm{OCH}_{3}$ were then obtained after a reaction time of $2 \mathrm{~h}$ (the reaction mixture was not stirred). In contrast with the behaviour of the system in the presence of air, no further "borohydride consumption" was now observed after prolonged reaction times (Fig. 2, curve $c$ ).

* Kindly carried out by Metallografiska Institutet, Stockholm. 


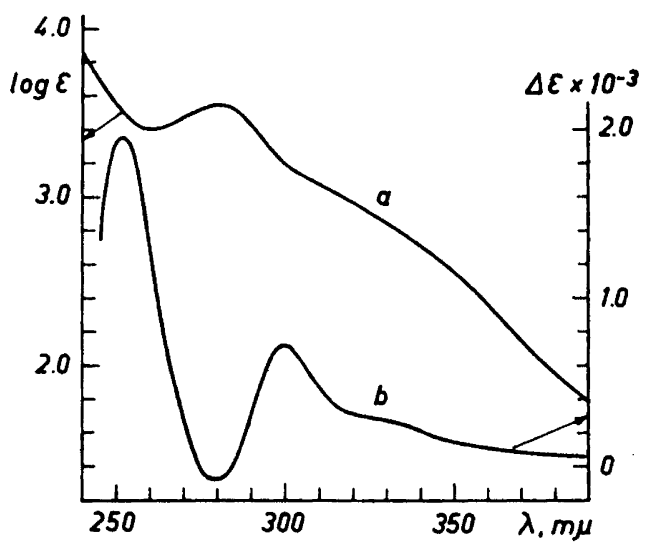

Fig. 3. Ultraviolet absorption (curve $a$ ) and ionisation- $\Delta \varepsilon$ curve $(b)$ of Björkman lignin treated $1 \mathrm{~h}$ with $\mathrm{KBH}_{4}$ under the conditions given for Fig. 2, curve $c$. ( $\varepsilon$ values based on $\mathrm{OCH}_{3}$ concentration.) Neutral solvent, ethanol-ethylcellosolve (9:1); alkaline solvent, $0.1 \mathrm{~N} \mathrm{NaOH}$ in ethanol-ethylcellosolve-water (4:1:5).

These results clearly show that the borohydride determination of carbonyl groups in Björkman lignin will yield erroneously high values if air is not excluded from the apparatus. Although the value obtained with the apparatus filled with $\mathrm{N}_{2}$ or $\mathrm{H}_{2}$ (mean, $0.28 \mathrm{CO} / \mathrm{OCH}_{3}$ ) could be expected to be close to the actual carbonyl content of the lignin, it was still higher than that obtained by the oximation method $(0.20)$. It was found, however, that a sodium borohydride-reduced lignin, although devoid of carbonyl groups, in the apparatus filled with $\mathrm{H}_{2}$ or $\mathrm{N}_{2}$, still gave apparent values of $0.04-0.08 \mathrm{CO} / \mathrm{OCH}_{3}$, after a reaction period of $5 \mathrm{~h}$. This may possibly be ascribed to incomplete removal of air from the apparatus. [The mean of these values has been taken in curve c, Fig. 2, as the "zero time" value. Similarly, the "zero time" values for curves $a$ and $b$ are those obtained in $5 \mathrm{~h}$ experiments in air with $\mathrm{NaBH}_{4}$-lignin without stirring $(a)$ and with stirring $(b)$.] Correction of the final value obtained for Björkman lignin in hydrogen or nitrogen atmosphere $\left(0.28 \mathrm{CO} / \mathrm{OCH}_{2}\right)$ for the corresponding $5 \mathrm{~h}$ value for $\mathrm{NaBH}_{4}$-lignin $\left(0.04-0.08 \mathrm{CO} / \mathrm{OCH}_{3}\right)$ would yield a value of $0.20-0.24 \mathrm{CO} / \mathrm{OCH}_{3}$, with would be in accordance with the oximation value.

A lignin preparation which was recovered from a borohydride experiment after one hours' reduction time, exhibited the UV absorption and ionisation $\Delta \varepsilon$-curves shown in Fig. 3. Similar curves were obtained for products obtained after longer periods of reaction. Surprisingly enough, the $\Delta \varepsilon$-curve (Fig. 3, curve $b$ ) showed that the phenolic aryl-aketone groups were completely reduced already after one hour, no $\Delta \varepsilon$-maximum being found at $357 \mathrm{~m} \mu$ (cf. the ionisation $\Delta \varepsilon$-curve of untreated Björkman lignin ${ }^{3}$ ). As shown in Part I 2, the borohydride reduction of 4-hydroxyphenyl ketones proceeds more slowly than that of the non-phenolic analogues, the half-time value for the reduction of ketone III, for instance, being $10 \mathrm{~h}$ at $\mathrm{pH} 12$, and considerably higher at $\mathrm{pH} 13$. The rapid reduction of phenolic aryl-a-ketone groupings in lignin, as observed in the volumetric experiments, seems to be attributable to the comparatively low $\mathrm{pH}$ (about 11.2) of the reaction mixture used. This finding also seems to indicate that the value of about $0.24 \mathrm{CO} / \mathrm{OCH}_{3}$, 


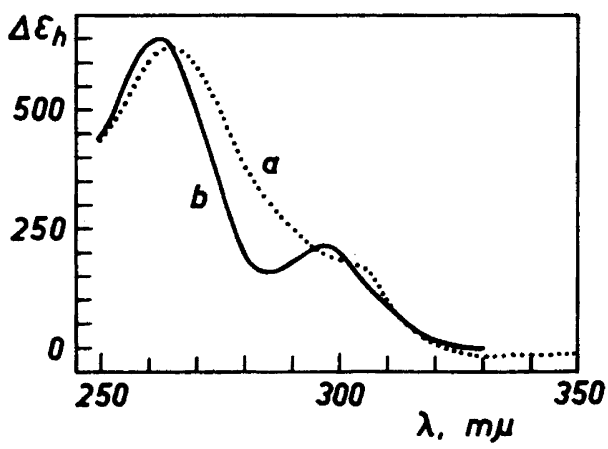

Fig. 4. Curve $a$ : Hydrogenation- $\Delta \varepsilon$ curve of Björkman lignin pretreated $5 \mathrm{~h}$ with $\mathrm{KBH}_{4}$ under $\mathrm{N}_{2}$ (exptl. conditions as described for curve $c$, Fig. 2). Hydrogenation in $93 \%$ HOAc over Pd-BaSO, (see Experimental). Curve $b$ : Hydrogenation- $\Delta \varepsilon$ curve of 0.04 mole/l isopropylconiferyl alcohol (cf. Ref. ${ }^{3}$ ).

as obtained after one hour's reaction in a $\mathrm{N}_{2}$ or $\mathrm{H}_{2}$ atmosphere (Fig. 2, curve $c$ ) is closer to the actual CO content of the lignin than the final value $(0.28)$, the gas-consuming. side-reactions evidently proceeding more slowly than the borohydride reduction of the carbonyl groups.

By means of the borohydride reduction- $\Delta \varepsilon$ method ${ }^{2}$, it could further be demonstrated that, as expected, the non-phenolic aryl- $a$-ketone groupings as well as the coniferyl aldehyde groupings had disappeared after on hour's reduction time.

As hydrogen is transferred to ethylenic bonds by the catalytic action of nickel boride ${ }^{12,13,3}$, it could be suspected that, in the volumetric carbonyl analysis, some hydrogen night be consumed by similar reaction of double bonds in the lignin, thus contributing to the high apparent carbonyl values obtained. An attempt was therefore made to determine, in a recovered lignin product, the number of ethylenic groups conjugated with the aromatic nucleus. The product was hydrogenated over $\mathbf{P d}-\mathrm{BaSO}_{4}$, as described in the preceding paper ${ }^{3}$, and the hydrogenation- $\Delta \varepsilon$ curve $\left(\Delta \varepsilon_{\mathrm{h}}\right.$ curve) was constructed (Fig. 4, curve a). It indicated the presence of about 0.04 coniferyl alcohol groups per $\mathrm{OCH}_{3}$. (For comparison, the wavelength curve of the $\Delta \varepsilon_{\mathrm{h}}$ values, multiplied by 0.04 , for isopropylconiferyl alcohol ${ }^{3}$, bas been given in Fig. 4, curve b.) For a borohydridereduced lignin, a somewhat higher value for the coniferyl alcohol groups, viz., $0.06-0.08$, would be expected, $0.03-0.04$ being present in untreated lignin and a similar number being formed by the reduction of the coniferyl aldehyde groups ${ }^{3}$. The value obtained $(0.04)$ then would indicate that catalytic hydrogenation of $0.02-0.04$ coniferyl alcohol side-chains has taken place under the conditions of the carbonyl determination method. Although the latter figures may be within the limits of error of this method, it seems possible that a minor fraction $(0.02-0.04)$ of the CO values obtained after the exclusion of air actually should be ascribed to ethylene groups.

To summarise, the IR studies as well as the volumetric CO determination carried out with the exclusion of oxygen have confirmed that Björkman lignin contains about $0.20 \mathrm{CO} / \mathrm{OCH}_{3}$, as found previously with the hydroxylamine hydrochloride method ${ }^{1}$. The IR studies have further provided new evidence for the correctness of the finding ${ }^{2,3}$ that these carbonyl groups consist of 0.03 0.04 coniferyl aldehyde groups, about 0.07 aryl $a$-ketone groupings and about $0.10 \beta$-ketone groupings. As shown by the spectrochemical borohydride $\left(\Delta \varepsilon_{\mathrm{r}}\right)$ and hydrogenation $\left(\Delta \varepsilon_{\mathrm{h}}\right)$ methods ${ }^{2,3}$, only about 0.01 coniferyl aldehyde groups and about 0.01 aryl-a-ketone groups have free phenolic hydroxyl groups.

Acta Chem. Scand. 15 (1961) No. 2 


\section{EXPERIMENTAL}

Infrared spectra were recorded on a Perkin-Elmer model 21 instrument; $\mathrm{KBr}$ discs were used. The mixtures of model substances and $\mathrm{NaBH}_{4}$-reduced lignin (Fig. 1) were made from the desired amounts of $1 \%$ mixtures of the model substances in $\mathrm{KBr}$ and a lignin- $\mathrm{KBr}$ mixture, all mixtures being prepared by means of a vibrator. The total amount of organic material was $1.80 \mathrm{mg}$ per $500 \mathrm{mg}$ of $\mathrm{KBr}$.

Ultraviolet absorption was measured with a Beckman DU spectrophotometer.

For the isolation of the reduced lignin, the potassium borohydride reaction mixture was acidified with acetic acid, the alcohol removed under reduced pressure and the lignin precipitate recovered as described in Part III ${ }^{3}$ for similar preparation of $\mathrm{NaBH}_{4}$-reduced lignin.

The $U V$ absorption of the reduced lignin (Fig. 3) was measured in a neutral solution, obtained by dissolving $5.00 \mathrm{mg}$ of the lignin in $5 \mathrm{ml}$ of freshly distilled methylcellosolve and making up the mixture to $100 \mathrm{ml}$ with $95 \%$ ethanol (curve $a$ ), and in an alkaline solution containing $5.00 \mathrm{mg}$ of the lignin in $100 \mathrm{ml}$ of $0.1 \mathrm{~N} \mathrm{NaOH}$ in $50 \%$ aqueous ethanol. The difference values between the $\varepsilon$ values of the latter absorption curve and curve $a$ gave the ionisation- $\Delta \varepsilon$ curve $(b)$.

The hydrogenation- $\Delta \varepsilon$ curve of the $\mathrm{KBH}_{4}$-reduced lignin (Fig. 4, a) was obtained as follows. The recovered lignin preparation $(0.1 \mathrm{~g})$, dissolved in $93 \%$ aqueous acetic acid, was hydrogenated for $6 \mathrm{~h}$ at room temperature over $\mathrm{PdCl}_{2}-\mathrm{BaSO}_{4}(0.5 \mathrm{~g})$, as described before ${ }^{3,13}$. The catalyst was centrifuged off and washed, and the absorption was measured in a sample of the solution diluted with ethanol to contain about $0.05 \mathrm{~g}$ lignin/l. By subtracting the values obtained from those determined for the non-hydrogenated product, the $\Delta \varepsilon_{\mathbf{h}}$ curve was constructed.

The volumetric borohydride method. The experiments for curve $a$, Fig. 2, were carried out according to Gierer and Söderberg ' ; in those for curve $b$, magnetic stirring of the solution was applied. If air had to be excluded, as in the experiments to curve $c$, the apparatus was evacuated by a water suction pump and refilled (five times) with nitrogen or hydrogen, before the borohydride and lignin solutions were mixed in the reaction vessel.

The authors wish to thank Mrs. Terezia Marton, who has carried out the infrared work and the hydroxyl group determinations. Financial support from Statens Tekniska Forskningsråd is gratefully acknowledged.

\section{REFERENCES}

1. Adler, E. and Walldén, I., quoted in Adler, E. and Gierer, J., in Treiber, E. Die Chemie der Pflanzenzellwand, Springer-Verlag, Berlin 1957, p. 446.

2. Adler, E. and Marton, J. Acta Chem. Scand. 13 (1959) 75. [Preliminary report, Marton, J. Proc. IVth Intern. Congr. Biochem., Vienna 1958, vol. II (1959) 154.]

3. Marton, J. and Adler, E. Acta Chem. Scand. 15 (1961) 370.

4. Gierer, J. and Söderberg, S. Acta Chem. Scand. 13 (1959) 127.

5. Lindberg, B. and Misiorny, A. Svensk Papperstidn. 55 (1952) 13; Lindberg, B. and Theander, O. Ibid. 57 (1954) 83.

6. Adler, E., Pepper, J. M. and Eriksoo, E. Ind. Eng. Chem. 49 (1957) 1391.

7. Adler, E. and Walldén, I. Unpublished.

8. Pearl, J. J. Org. Chem. 24 (1959) 736.

9. Freudenberg, K. and Schlüter, H. Chem. Ber. 88 (1955) 617; note, p. 618.

10. Björkman, A. and Person, B. Svensk Papperstidn. 60 (1957) 158.

11. Anet, F. A. L. and Robinson, R. J.Chem. Soc. 1955 2253; Fritz, H., Beach, E. and Wieland, Th. Angew. Chem. 71 (1959) 126.

12. Paul, R., Buisson, P. and Joseph, N. Compt. rend. 232 (1951) 627; Ind. Eng. Chem. $44(1952) 1006$.

13. Adler, E. and Marton, J. Acta Chem. Scand. 15 (1961) 357.

14. Gaylord, N. G. Reduction with Complex Metal Hydrides, Interscience Publ., New York 1956, pp. 60-61; Levy, A., Brown, J. B. and Lyons, C. J. Ind. Eng. Chem. 52 (1960) 211 .

Received October 3, 1960.

Acta Chem. Scand. 15 (1961) No. 2 